\title{
Erratum to: Reformation of tissue balls from tentacle explants of coral Goniopora lobata: self-organization process and response to environmental stresses
}

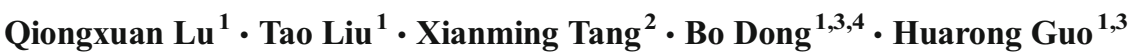

Published online: 28 October 2016

(C) The Society for In Vitro Biology 2016

Erratum to: In Vitro Cell. Dev. Biol.-Animal

DOI 10.1007/s11626-016-0095-0

In the Acknowledgments paragraph on page 11 the following repeated text needs to be removed:

This work is supported by National Natural Science Foundation of China (Grant No. 31472274 and 31172391), Regional Demonstration of Marine Economy Innovative Development Project (No.12PYY001SF08), National Hightech R\&D Program of China (863 Program; Grant No. 2012AA10A402), and open funds of Institute of biodiversity and evolution, Ocean University of China (Grant No. 201362017). B. Dong is supported by Taishan Scholar Program of Shandong Province.

The online version of the original article can be found at doi:10.1007/s11626-016-0095-0.

Bo Dong

bodong@ouc.edu.cn

$\triangle$ Huarong Guo

huarongguo@ouc.edu.cn

1 Ministry of Education Key Laboratory of Marine Genetics and Breeding, College of Marine Life Sciences, Ocean University of China, Qingdao 266003, China

2 Hainan Academy of Ocean and Fisheries Sciences, Haikou 570203, China

3 Institute of Evolution and Marine Biodiversity, Ocean University of China, Qingdao 266003, China

4 Laboratory for Marine Biology and Biotechnology, Qingdao National Laboratory for Marine Science and Technology,

Qingdao, China 